\title{
Is there an indication for coronary angiography in patients under 60 years of age with no or minimal angina pectoris after a first myocardial infarction?
}

\author{
Th W G VEENBRINK, T VAN DER WERF, P W WESTERHOF, E O ROBLES DE MEDINA, \\ F L MEIJLER \\ From the Department of Cardiology, University Hospital, Utrecht, The Netherlands
}

SUMMARY Coronary angiography and exercise stress tests were performed in 91 consecutive patients under 60 years of age having either no or only mild angina pectoris with or without medication after a first myocardial infarction. Nine $(10 \%)$ patients had angiographic high risk coronary artery disease defined as three vessel disease, left main stenosis, or proximal stenosis of the left anterior descending artery. Eighteen patients had a positive electrocardiographic exercise stress test, including eight of the nine patients with angiographic high risk coronary artery disease.

It may be concluded therefore that coronary angiography to detect high risk coronary artery disease in this group can be restricted to patients with a positive exercise stress test. This policy would obviate the need for about $80 \%$ of coronary angiograms performed in this age group.

The indication for coronary angiography in patients after a first myocardial infarction, with no or only mild angina pectoris, remains controversial. ${ }^{1-6}$ In patients with severe angina, there is a clear indication for coronary angiography to determine their suitability for surgery. Although patients with no or only mild angina pectoris are not candidates for coronary artery bypass surgery on the basis of symptoms, severe coronary artery disease may be present despite their apparently minor symptoms. ${ }^{6-8}$ In some cardiac centres all patients under a certain age with evidence of coronary artery disease in the absence of specific contraindications are examined by coronary angiography in order to detect high risk disease.

High risk coronary artery disease is defined as: three vessel disease, proximal stenosis of the left anterior descending artery, or stenosis in the left main coronary artery (see methods). In these patients surgery has been shown to prolong life expectancy. ${ }^{9-16}$ Our study was performed in order to determine the incidence of high risk coronary artery

Requests for reprints to $\mathrm{Dr}$ Th W G Veenbrink, Academisch Ziekenhuis, Catharijnesingel 101, 3511 GV Utrecht, The Netherlands.

Accepted for publication 14 August 1984 disease in patients under 60 years of age without or with only mild angina pectoris after a first myocardial infarction and whether or not the existence of high risk coronary artery disease could be predicted from the results of electrocardiographic exercise stress testing.

\section{Patients and methods}

\section{PATIENT SELECTION}

Only patients, under 60 years of age, who sustained a first transmural myocardial infarction in the period January 1982 to October 1983, with no or with only mild angina pectoris (New York Heart Association functional class I or II for angina pectoris) irrespective of treatment were considered eligible. Patients with valvar heart disease, congestive heart failure, left bundle branch block, or associated severe non-cardiac disease such as malignancy, insulin dependent diabetes, or severe hypertension were excluded from the study. Cardiac catheterisation and coronary angiography were performed about two months after acute myocardial infarction. Ninety one patients entered the study. Before cardiac catheterisation and coronary angiography all patients underwent electrocardiographic exercise testing. If patients were receiving medication this was not withdrawn. 


\section{EXERCISE TESTING}

All patients underwent a symptom limited exercise stress test to detect a possible discrepancy between subjective and objective signs of coronary insufficiency. The stress test was performed using either a treadmill (with the graded multistage exercise protocol of Bruce) or a graded bicycle ergometric exercise test $(10 \mathrm{~W} / \mathrm{min})$. Every three minutes a complete 12 lead electrocardiogram was recorded and blood pressure measured.

In the absence of electrocardiographic signs of coronary insufficiency, irrespective of whether or not patients reached $85 \%$ of the predicted maximal heart rate, the stress test was considered to be negative. The test was considered to be inconclusive if the electrocardiogram showed ST segment elevation in leads over the infarcted area accompanied by reciprocal ST segment depression. Several authors have attributed these ST segment elevations to abnormal left ventricular wall motion. ${ }^{17-19}$

Electrocardiographic signs of coronary insufficiency were defined as: $(a) \mathrm{J}$ point depression of $\geqslant 0.1$ $\mathrm{mV}$ relative to the end of the $P Q$ segment, with horizontal or downward sloping ST segment, ${ }^{2021}$ or $(b) U$ wave inversion, ${ }^{22}$ or (c) a slow upsloping ST segment depression $\geqslant 0.2 \mathrm{mV}$ for at least $0.08 \mathrm{~s}$ beyond the $\mathrm{J}$ point, ${ }^{2324}$ or $(d)$ an increase of $\geqslant 0.2 \mathrm{mV}$ for at least $0.08 \mathrm{~s}$ after the $\mathrm{J}$ point in cases of preexisting ST segment depression.

\section{LEFT VENTRICULOGRAPHY AND CORONARY ANGIOGRAPHY}

The left ventricle was visualised in the frontal and lateral projections. The segmental contractililty was classified as normal, hypokinetic, akinetic, or dyskinetic. Coronary angiography was performed by either the Sones' or Judkins' technique. In addition to the standard posterior-anterior and oblique projections, angulated views were also used.

In patients with normal coronary arteries an ergonovine provocation test was performed 48 hours after stopping all medication. Increasing doses of $0.05,0.1$, and $0.2 \mathrm{mg}$ ergonovine maleate were injected intravenously under electrocardiographic control and recording of symptoms.

Coronary stenoses resulting in more than a $70 \%$ reduction of luminal diameter in any projection were considered to be haemodynamically important. ${ }^{25} 26$ Only the most severe narrowing in each coronary artery was counted. Left main stenosis was counted as two vessel disease and was considered to be present when the luminal diameter was reduced by more than $50 \%$, as commonly accepted. Stenoses of angiographically large diagonal or marginal branches were considered as lesions of the left anterior descending and circumflex coronary arteries respectively. Patients were classified as having one vessel, two vessel, or three vessel disease.

High risk coronary artery disease was defined as: (a) three vessel disease-all vessels having a narrowing $>70 \%$, (b) left main stenosis $>50 \%$, (c) proximal stenosis of the left anterior descending artery with a $70-99 \%$ narrowing before take off of the first large septal perforator without prior anterior wall infarction, and $(d)$ any combinations of the above.

\section{STATISTICAL METHODS}

The results were analysed by the $\chi^{2}$ test. A p value $<0.05$ was considered to be significant.

\section{Results}

CLINICAL CHARACTERISTICS

The mean age of the 91 patients $(88 \mathrm{men}$, three women) was 48 (range 34-59) years. Of these, 51 sustained an inferior wall infarction and 40 an anterior wall infarction. Seventy patients were in NYHA functional class I and 21 in functional class II for angina pectoris (Table 1).

\section{FINDINGS AT CORONARY ANGIOGRAPHY}

Table 2 summarises the findings.

All patients-Four patients had completely normal vessels, including one with an aberrant origin of the right circumflex artery. Another patient had $<70 \%$ stenoses. All these patients underwent an ergonovine provocation test, which appeared to be negative in all cases. High risk coronary artery disease was present in nine patients; four had left anterior descending artery stenosis and five three vessel disease, including two patients with associated left main stenosis.

Functional class-High risk coronary artery disease was present in five out of 70 asymptomatic patients (class I) and in four out of 21 with mild angina pectoris (class II). This difference is not significant. Two patients with left main artery stenosis were asymptomatic.

Site of infarction-Seven out of nine patients with high risk coronary artery disease had sustained an inferior wall infarction: four patients had proximal stenosis of the left anterior descending artery and three had three vessel disease, including the two patients with left main stenosis. None of the patients

Table 1 NYHA functional class of symptoms related to the site of the infarction

\begin{tabular}{llll}
\hline Site & $\begin{array}{l}\text { No of } \\
\text { patients }\end{array}$ & Class I & Class II \\
\hline Inferior & 51 & 39 & 12 \\
Anterior & 40 & 31 & 9 \\
Total & 91 & 70 & 21 \\
\hline
\end{tabular}


Table 2 Angiographic findings

\begin{tabular}{|c|c|c|c|}
\hline \multirow{2}{*}{$\begin{array}{l}\text { No of } \\
\text { diseased } \\
\text { vessels }\end{array}$} & \multirow{2}{*}{$\begin{array}{l}\text { No of } \\
\text { patients }\end{array}$} & \multicolumn{2}{|l|}{ Including stenosis of: } \\
\hline & & $\begin{array}{l}\text { Left anterior descending } \\
\text { artery }\end{array}$ & $\begin{array}{l}\text { Left main } \\
\text { artery }\end{array}$ \\
\hline \multicolumn{4}{|c|}{ All patients $(n=91)$} \\
\hline 0 & 5 & - & - \\
\hline$\frac{1}{2}$ & $\begin{array}{l}63 \\
18\end{array}$ & $\overline{4^{\star}}$ & $\bar{z}$ \\
\hline 3 & $5^{\star}$ & $\div$ & $\overline{2 \star}$ \\
\hline \multicolumn{4}{|c|}{ Patients in class $I(n=70)$} \\
\hline $\begin{array}{l}0 \\
1\end{array}$ & 5 & - & - \\
\hline$\frac{1}{2}$ & $\begin{array}{l}49 \\
14\end{array}$ & $\overline{3^{\star}}$ & $\overline{-}$ \\
\hline 3 & $2^{\star}$ & - & $2 \star$ \\
\hline \multicolumn{4}{|c|}{ Patients in class $I I(n=21)$} \\
\hline $\begin{array}{l}0 \\
1\end{array}$ & $\begin{array}{r}0 \\
14\end{array}$ & 二 & 二 \\
\hline 2 & 4 & $1^{\star}$ & - \\
\hline 3 & $3^{\star}$ & - & - \\
\hline \multicolumn{4}{|c|}{ Patients with inferior infarction $(n=51)$} \\
\hline $\begin{array}{l}0 \\
1\end{array}$ & $\begin{array}{r}1 \\
36\end{array}$ & 二 & - \\
\hline 2 & $\begin{array}{l}30 \\
11\end{array}$ & $\overline{4^{\star}}$ & $\bar{z}$ \\
\hline 3 & $3 *$ & - & $2 \star$ \\
\hline \multicolumn{4}{|c|}{ Patients with anterior infarction ( $n=40$ ) } \\
\hline $\begin{array}{l}0 \\
1\end{array}$ & $\begin{array}{r}4 \\
27\end{array}$ & - & 一 \\
\hline 2 & 7 & 二 & $\bar{z}$ \\
\hline 3 & $2^{\star}$ & - & - \\
\hline
\end{tabular}

$\star$ High risk coronary artery disease.

with previous anterior wall infarction had left main disease or proximal stenosis of the left anterior descending artery in the sense of high risk disease. If the left anterior descending artery was occluded or supplied the infarcted area this was not considered to be in the high risk category. The difference in the incidence of high risk disease between patients with previous inferior or anterior wall infarction was not significant.

\section{EARLY COMPLICATIONS OF CARDIAC CATHETERISATION}

Three patients developed early complications after catheterisation: one required surgical correction of a pseudoaneurysm of the femoral artery, and two had reversible glottic oedema and shock attributable to an allergic reaction to the contrast material.
FINDINGS AT EXERCISE STRESS TESTING

Nine of the 70 patients who were in functional class I had a positive stress test as did nine of the 21 patients in class II (Table 3). This difference is significant $(p<0.01)$. All patients showed a normal blood pressure response during exercise. No attempt was made to record the differences between maximal heart rate and duration of exercise in relation to the method of stress testing used.

Only six patients with one vessel disease had a positive stress test, whereas all the patients with three vessel disease, including two with left main stenosis, had a positive exercise response. Three of the four patients with proximal stenosis of the left anterior descending artery had a positive stress test. None of the patients with an inconclusive test had high risk disease.

In 18 patients the exercise test was positive, including eight of the nine patients with high risk disease. Only one patient with high risk disease had a negative stress test. The difference in incidence of high risk disease in patients with a positive exercise test compared with those with a negative test is significant $(p<0.001)$.

Thirteen of 15 patients with an inconclusive test had previously sustained an anterior wall infarction and two an inferior wall infarction. After previous anterior wall infarction 10 patients had one vessel disease and three two vessel disease. Of the remaining two patients after inferior wall infarction, one had one vessel disease and the other two vessel disease. At left ventriculography dyskinesia of the infarcted area was found in 12 patients and akinesia in three.

\section{Discussion}

This study was performed to document angiographically the incidence of high risk coronary artery disease in patients under 60 years of age having no or only mild angina pectoris after first transmural myocardial infarction and to relate this to the results of exercise stress testing.

Table 3 Results of exercise stress test in relation to functional class and number of diseased vessels

\begin{tabular}{|c|c|c|c|c|}
\hline \multirow[t]{2}{*}{ Variable } & \multirow{2}{*}{$\begin{array}{l}\text { No of } \\
\text { patients }\end{array}$} & \multicolumn{3}{|c|}{ Test result: } \\
\hline & & Positive & Negative & Inconclusive \\
\hline $\begin{array}{l}\text { Functional class: } \\
\text { I } \\
\text { II } \\
\text { Total }\end{array}$ & $\begin{array}{l}70 \\
21 \\
91\end{array}$ & $\begin{array}{r}9 \\
9 \\
18\end{array}$ & $\begin{array}{r}49 \\
9 \\
58\end{array}$ & $\begin{array}{r}12 \\
3 \\
15\end{array}$ \\
\hline $\begin{array}{l}\text { No of diseased vessels: } \\
0 \\
1 \\
2 \\
3\end{array}$ & $\begin{array}{r}5 \\
63 \\
18 \\
5\end{array}$ & $\begin{array}{l}0 \\
6 \\
7 \star \\
5\end{array}$ & $\begin{array}{c}5 \\
46 \\
7 \dagger \\
0\end{array}$ & $\begin{array}{r}0 \\
11 \\
4 \\
0\end{array}$ \\
\hline
\end{tabular}

^Including three patients with stenosis of the left anterior descending artery.

tIncluding one patient with stenosis of the left anterior descending artery. 
Previous studies-the European coronary surgery study group, ${ }^{12}$ the Veterans Administration study, ${ }^{10}$ the Seattle Heart Watch, ${ }^{11}$ and Sheldon et al ${ }^{16}$ suggest that life expectancy might be prolonged by operation in patients with stable angina pectoris and associated left main stenosis, three vessel disease, or proximal left anterior descending stenosis. On the other hand the latest Coronary Artery Surgery Study fails to show an improved five year survival after coronary artery bypass surgery in patients with no or mild angina pectoris with either three vessel disease or proximal left anterior descending artery stenosis. ${ }^{27}$ Nevertheless, as only $37 \%$ of the patients who were eligible were actually studied, the question of whether these results are valid remains.

Comparison of our results with other reported studies is hampered by differences of definition as to what constitutes a haemodynamically important stenosis (Table 4). Mautner and Phillips considered a $>70 \%$ cross sectional narrowing haemodynamically important, corresponding to a $50 \%$ narrowing in luminal diameter. ${ }^{28}$ Vanhaecke et al considered a $>50 \%$ diameter narrowing as haemodynamically important. ${ }^{29}$ For the purposes of this study we chose a $>70 \%$ reduction in luminal diameter as being haemodynamically important. These differences probably explain the lower incidence of three vessel disease in our study, which is similar to that reported

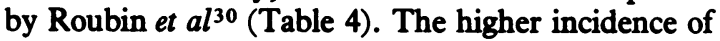
one vessel disease in our series might possibly be due to our criteria for patient selection. Firstly, all patients were under 60 years of age (mean 48 years). Chaitman et al reported a higher incidence of multivessel disease in patients over 55 years. ${ }^{31}$ In David's series, $18 \%$ of patients under 40 years of age had normal coronary angiograms. ${ }^{32}$ Secondly, all patients had recently sustained a first infarction. Roubin et al found a higher incidence of three vessel disease after second infarction. ${ }^{30}$ Thirdly, our patients had only mild or no angina, whereas Vanhaecke et al and
Chaitman et al found a higher incidence of three vessel disease in patients with more severe symptoms. ${ }^{2931}$

In the present study five of 70 patients without angina pectoris had high risk disease compared with four out of 21 with mild angina. This difference is not significant.

Several reports suggest a higher incidence of multivessel disease in patients after inferior wall infarction. ${ }^{31}{ }^{33}$ In our study 14 out of 51 patients who sustained inferior wall infarction had multivessel disease, including three with three vessel disease. Although nine of 40 patients after anterior wall infarction had multivessel disease, including two with three vessel disease these differences are not significant, as confirmed by Roubin et al, who also found no difference in the incidence of multivessel disease in patients with inferior wall infarction compared with patients with anterior wall infarction. ${ }^{30}$

Although the risk of morbidity related to cardiac catheterisation is low $2-3 \%, 3435$ the mortality, nevertheless, amounts to $0.2 \% .{ }^{3435}$ Bourassa and Noble found that mortality was closely related to the presence of left main coronary artery stenosis. ${ }^{35}$ In our study no patient died, and the complication rate was $3 \%$.

All patients with three vessel disease, including the two with left main stenosis, had a positive exercise stress test, even when taking medication. This agrees with the results of Weiner et al, who, using only a horizontal ST segment depression of $>0.1 \mathrm{mV}$, found that $97 \%$ of the patients with left main stenosis and $96 \%$ of the patients with three vessel disease had a positive result. ${ }^{36}$ Similarly three of the four patients with a proximal left anterior descending artery stenosis had a positive stress test, which is in accordance with the results of Chaitman $e t$ al, who found a positive test in $86 \%$ of the patients with proximal left anterior descending artery stenosis. ${ }^{31}$

It would, therefore, appear that the existence of left

Table 4 Review of published studies

\begin{tabular}{|c|c|c|c|c|c|c|c|}
\hline \multirow[t]{2}{*}{ Author } & \multirow{2}{*}{$\begin{array}{l}\text { No of } \\
\text { parients }\end{array}$} & \multirow{2}{*}{$\begin{array}{l}\text { Definition of } \\
\text { sigmificant } \\
\text { stenosis }\end{array}$} & \multirow{2}{*}{$\begin{array}{l}\text { Patient } \\
\text { characteristics }\end{array}$} & \multicolumn{4}{|c|}{$\%$ Of patients with ${ }^{\star}:$} \\
\hline & & & & $\begin{array}{l}\text { Normal } \\
\text { vessels }\end{array}$ & $\begin{array}{l}\text { One vessel } \\
\text { disease }\end{array}$ & $\begin{array}{l}\text { Two vessel } \\
\text { disease }\end{array}$ & $\begin{array}{l}\text { Three vessel } \\
\text { disease }\end{array}$ \\
\hline Roubin et $a^{30}$ & 202 & $\begin{array}{l}>70 \% \text { diameter } \\
\text { narrowing }\end{array}$ & $\begin{array}{l}\text { No, mild, or } \\
\text { severe angina, } \\
<60 \text { years }\end{array}$ & 7 & 62 & 24 & 7 \\
\hline Mautner and Phillips ${ }^{28}$ & 31 & $\begin{array}{l}>70 \% \text { cross } \\
\text { sectional } \\
\text { narrowing }\end{array}$ & $\begin{array}{l}\text { No or only mild } \\
\text { angina, }<65 \\
\text { years }\end{array}$ & 7 & 32 & 32 & 29 \\
\hline Vanhaecke et al ${ }^{2 y}$ & 59 & $\begin{array}{l}>50 \% \text { diameter } \\
\text { narrowing }\end{array}$ & $\begin{array}{l}\text { No angina, }<45 \\
\text { years }\end{array}$ & \multicolumn{2}{|l|}{51} & \multirow[t]{2}{*}{49} & \\
\hline Present study & 91 & $\begin{array}{c}>70 \% \text { diameter } \\
\text { narrowing }\end{array}$ & $\begin{array}{l}\text { No or only mild } \\
\text { angina, }<60 \text { years }\end{array}$ & $51 / 2$ & 69 & & $51 / 2$ \\
\hline
\end{tabular}

$\star$ Although the use of percentages calculated from populations of $<100$ is often misteading, vessel involvement is given as a percentage for comparison. 
main stenosis, three vessel disease, and in most cases also proximal left anterior descending artery stenosis can be predicted on the basis of a positive exercise test.

\section{CONCLUSION}

The indication for coronary angiography in patients under 60 years who have sustained a first myocardial infarction and who subsequently are either asymptomatic or have only mild angina pectoris is still controversial. Our study suggests that high risk coronary artery disease is seldom encountered in such patients. The presence of high risk disease is almost always associated with a positive exercise stress test. Although no mortality was associated with angiography in this study group, a 3\% early complication rate cannot be overlooked. Thus, bearing in mind both patient safety and cost containment, we conclude that in this patient population coronary angiography to detect high risk disease should be limited to patients with a positive exercise test. This policy could be expected to save approximately $80 \%$ of angiograms in this patient population.

We thank B K Bootsma, Military Hospital, Utrecht; W A A J van Ekelen, St Anna Hospital, Geldrop; F M A Harms, Oudenrijn Hospital, Utrecht; and $M J$ van der Horst, St Anna Hospital, Geldrop; who allowed their patients to be included in this study.

\section{References}

1 Bristow JD, Burchell HB, Campbell RW, et al. (Report of the ad hoc committee of the Council on Clinical Cardiology of the American Heart Association.) Indication for coronary arteriography. Circulation 1977; 55: 969A74A.

2 Turner JD, Rogers WJ, Mantle JA, Rackley CE, Russell RO Jr. Coronary angiography soon after myocardial infarction. Chest 1980; 77: 58-65.

3 Rahimtoola SH. Coronary arteriography in asymptomatic patients after myocardial infarction. Chest 1980; 77: 53-7.

4 Mautner RK. Routine coronary arteriography post myocardial infarction. Cathet Cardiovasc Diagn 1982; 8: 217-21.

5 Gault JH. Routine coronary arteriography post myocardial infarction: another view. Cathet Cardiovasc Diagn 1982; 8: 223-4.

6 Mautner RK. Routine coronary arteriography in asymptomatic postinfarction patients [Letter]. Chest 1981; 79: 126-7.

7 Master AM, Geller AJ. The extent of completely asymptomatic coronary artery disease. Am $\mathcal{F}$ Cardiol 1969; 23: 173-9.

8 Froelicher VF Jr, Yanowitz FG, Thompson AJ, Lancaster MC. The correlation of coronary angiography and the electrocardiographic response to maximal treadmill test- ing in 76 asymptomatic men. Circulation 1973; 48: 597604.

9 Hammermeister KE, De Rouen TA, Dodge HT. Effect of coronary surgery on survival in asymptomatic and minimally symptomatic patients. Circulation 1980; 62 (suppl I): 98-102.

10 Takaro T, Hultgren HN, Detre KM, Peduzzi P. The veterans administration cooperative study of stable angina: current status. Circulation 1982; 65 (suppl II): 60-7.

11 Hammermeister KE, DeRouen TA, Dodge HT. Comparison of survival of medically and surgically treated coronary disease patients in Seattle Heart Watch: a nonrandomized study. Circulation 1982; 65 (suppl II): 53-9.

12 European Coronary Surgery Study Group. Prospective randomized study of coronary artery bypass surgery in stable angina pectoris: a progress report on survival. Circulation 1982; 65 (suppl II): 67-72.

13 Chaitman BR, Fisher LD, Bourassa MG, et al. Effect of coronary bypass surgery on survival patterns in subsets of patients with left main coronary artery disease. Report of the collaborative study in coronary artery surgery (CASS). Am 7 Cardiol 1981; 48: 765-77.

14 Takaro T, Hultgren HN, Lipton MJ, et al. The VA cooperative randomized study of surgery for coronary arterial occlusive disease. II Subgroup with significant left main lesions. Circulation 1976; 54 (suppl III): 10717.

15 European coronary surgery study group. Prospective randomised study of coronary artery bypass surgery in stable angina pectoris. Second interim report. Lancet 1980; ii: 491-5.

16 Sheldon WC, Rincon G, Pichard AD, Razavi M, Cheanvechai C, Loop FD. Surgical treatment of coronary artery diseae: pure graft operations, with a study of 741 patients followed 3-7 years. Prog Cardiovasc Dis 1975; 18: 237-53.

17 Castellanet MJ, Greenberg PS, Ellestad MH. Comparison of ST segment changes on exercise testing with angiographic findings in patients with prior myocardial infarction. Am $\mathcal{Y}$ Cardiol 1978; 42: 29-35.

18 Paine TD, Dye LE, Roitman DI, et al. Relation of graded exercise test findings after myocardial infarction to extent of coronary artery disease and left ventricular dysfunction. Am $\mathcal{F}$ Cardiol 1978; 42: 716-23.

19 Lahiri A, Balasubramanian V, Millar MWC, Crawley J, Raftery EB. Exercise-induced ST segment elevation. Electrocardiographic, angiographic, and scintigraphic evaluation. Br Heart $f$ 1980; 43: 582-8.

20 Martin CM, McConahay DR. Maximal treadmill exercise electrocardiography; correlations with coronary arteriography and cardiac hemodynamics. Circulation 1972; 46: 956-62.

21 Piessens J, van Mieghem, Kesteloot $\mathbf{H}$, de Geest $\mathbf{H}$. Diagnostic value of clinical history, exercise testing and atrial pacing in patients with chest pain. Am $\mathcal{F}$ Cardiol 1974; 33: 351-6.

22 Gerson MC, Phillips JF, Morris SN, McHenry PL. Exercise induced U-wave inversion as a marker of stenosis of the left anterior descending coronary artery. Circulation 1979; 60: 1014-20.

23 Stuart RJ Jr, Ellestad MH. Upsloping ST-segments in 
exercise stress testing. Six year follow-up study of 438 patients and correlation with 248 angiograms. Am $\mathcal{F}$ Cardiol 1976; 37: 19-22.

24 Rijneke RD, Ascoop CA, Talmon IC. Clinical significance of upsloping ST segments in exercise electrocardiography. Circulation 1980; 61: 671-8.

25 Brown BG, Bolson E, Frimer M, Dodge HT. Quantitative coronary arteriography: estimation of dimensions, hemodynamic resistance and atheroma mass of coronary artery lesions, using the arteriogram and digital computation. Circulation 1977; 55: 329-37.

26 McMahon M, Brown BG, Rolett E, Bolson E, Frimer M, Dodge HT. Quantitative links between the severity of coronary stenosis and clinical syndromes of coronary disease [Abstract]. Circulation 1977; 56 (suppl III): 238.

27 CASS principal investigators and their associates. Coronary Artery Surgery Study (CASS): a randomized trial of coronary artery bypass surgery. Survival data. Circulation 1983; 68: 939-50.

28 Mautner RK, Phillips JH. Coronary angiography post first myocardial infarction in the asymptomatic or mildly symptomatic patient: clinical, angiographic and prospective observations. Cathet Cardiovasc Diagn 1981; 7: 1-11.

29 Vanhaecke J, Piessens J, Willems JL, De Geest H. Coronary arterial lesions in young men who survived a first myocardial infarction: clinical and electrocardiographic predictors of multivessel disease. Am $\mathcal{f}$ Cardiol
$1981 ; 47: 810-4$.

30 Roubin GS, Harris PJ, Bernstein L, Kelly DT. Coronary anatomy and prognosis after myocardial infarction in patients 60 years of age and younger. Circulation 1983; 67: 743-9.

31 Chaitman BR, Waters DD, Corbara F, Bourassa MG. Prediction of multivessel disease after inferior myocardial infarction. Circulation 1978; 57: 1085-90.

32 David GK. Myocardial infarction in young adults. Amsterdam, 1979. Thesis.

33 Miller RR, DeMaria AN, Vismara LA, et al. Chronic stable inferior myocardial infarction: unsuspected harbinger of high risk proximal left coronary arterial obstruction amenable to surgical revascularization. $A m \mathcal{F}$ Cardiol 1977; 39: 954-60.

34 Davis K, Kennedy JW, Kemp HG Jr, Judkins MP, Gosselin AJ, Killip T. Complications of coronary arteriography from the collaborative study of coronary artery surgery (CASS). Circulation 1979; 59: 1105-12.

35 Bourassa MG, Noble J. Complication rate of coronary arteriography. A review of 5250 cases studied by a percutaneous femoral technique. Circulation 1976; 53: 10614.

36 Weiner DA, McCabe CH, Ryan TJ. Identification of patients with left main and three vessel coronary disease with clinical and exercise test variables. Am $\mathcal{F}$ Cardiol 1980; 46: 21-7. 